\title{
Molecular Engineering Strategies for Symmetric Aqueous Organic Redox Flow
} Batteries

\author{
Fornari, Rocco Peter; Mesta, Murat; Hjelm, Johan; Vegge, Tejs; de Silva, Piotr
}

Published in:

ACS Materials Letters

Link to article, DOI:

10.1021/acsmaterialslett.0c00028

Publication date:

2020

Document Version

Peer reviewed version

Link back to DTU Orbit

Citation (APA):

Fornari, R. P., Mesta, M., Hjelm, J., Vegge, T., \& de Silva, P. (2020). Molecular Engineering Strategies for Symmetric Aqueous Organic Redox Flow Batteries. ACS Materials Letters , 2(3), 239-246.

https://doi.org/10.1021/acsmaterialslett.0c00028

\section{General rights}

Copyright and moral rights for the publications made accessible in the public portal are retained by the authors and/or other copyright owners and it is a condition of accessing publications that users recognise and abide by the legal requirements associated with these rights.

- Users may download and print one copy of any publication from the public portal for the purpose of private study or research.

- You may not further distribute the material or use it for any profit-making activity or commercial gain

- You may freely distribute the URL identifying the publication in the public portal 


\title{
Letter
}

\section{Molecular Engineering Strategies for Symmetric Aqueous Organic Redox Flow Batteries}

\author{
Rocco Peter Fornari, Murat Mesta, Johan Hjelm, Tejs Vegge, and Piotr de Silva
}

ACS Materials Lett., Just Accepted Manuscript • DOI: 10.1021/acsmaterialslett.0c00028 • Publication Date (Web): 07 Feb 2020

Downloaded from pubs.acs.org on February 13, 2020

\section{Just Accepted}

"Just Accepted" manuscripts have been peer-reviewed and accepted for publication. They are posted online prior to technical editing, formatting for publication and author proofing. The American Chemical Society provides "Just Accepted" as a service to the research community to expedite the dissemination of scientific material as soon as possible after acceptance. "Just Accepted" manuscripts appear in full in PDF format accompanied by an HTML abstract. "Just Accepted" manuscripts have been fully peer reviewed, but should not be considered the official version of record. They are citable by the Digital Object Identifier (DOI®). "Just Accepted" is an optional service offered to authors. Therefore, the "Just Accepted" Web site may not include all articles that will be published in the journal. After a manuscript is technically edited and formatted, it will be removed from the "Just Accepted" Web site and published as an ASAP article. Note that technical editing may introduce minor changes to the manuscript text and/or graphics which could affect content, and all legal disclaimers and ethical guidelines that apply to the journal pertain. ACS cannot be held responsible for errors or consequences arising from the use of information contained in these "Just Accepted" manuscripts. 


\title{
Molecular Engineering Strategies for Symmetric Aqueous Organic Redox Flow Batteries
}

\author{
Rocco Peter Fornari*, Murat Mesta, Johan Hjelm, Tejs Vegge, \\ Piotr de Silva* \\ Department of Energy Conversion and Storage \\ Technical University of Denmark \\ Anker Engelunds Vej 301, 2800 Kongens Lyngby, Denmark
}

ACS Paragon Plus Environment 
ABSTRACT: Symmetric aqueous organic redox flow batteries (RFBs) are potentially a cheap, durable and safe energy storage technology. Unlike normal asymmetric flow batteries, they are based on electrolytes that exist in at least three oxidation states and can undergo a minimum of two distinct redox processes. We compute the redox potentials of selected electrolytes intending to understand how the interaction between the redox units affects the potentials. We find that electronic interaction between redox units and intramolecular hydrogen bonding can both be exploited to tune the difference between the redox potentials, i.e. the theoretical voltage of the battery. The redox potentials can be further fine-tuned in either direction by adding substituents. Starting from these observations we formulate a set of rules which will help finding ideal candidates for symmetric RFBs.

TOC GRAPHICS

\section{NEGOLYTE POSOLYTE}

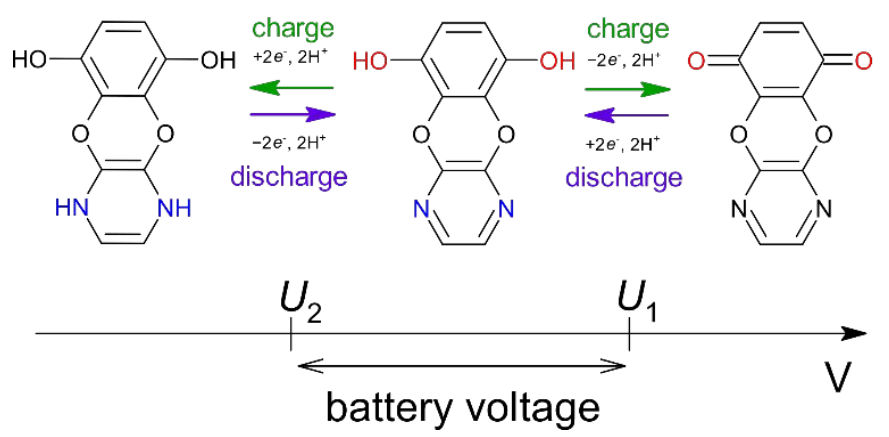

ACS Paragon Plus Environment 
Redox flow batteries (RFB) have the potential to become a longlasting, low-cost, easily scalable and safe energy storage technology. ${ }^{1}$ RFBs based on metal ions are already commercially available but have some drawbacks including highly volatile cost of the active material. ${ }^{1}$ Many alternative RFB concepts ${ }^{2}$ and active materials ${ }^{2,3}$ are currently being developed. All-organic aqueous RFBs, where both active materials are organic molecules, are under intense investigation ${ }^{4,5}$ since they hold promise to reduce the cost and the environmental footprint of RFBs. A major challenge for their development is the identification of suitable candidates for the redox-active molecules, which need to have suitable redox potentials, good solubility, long-term chemical stability and low crossover through the separator membrane. ${ }^{1,6}$ Computational studies have been used extensively to explore the chemical space of redoxactive molecules for RFBs. ${ }^{7-17}$ One promising strategy is finding redox molecules which have two redox processes, which could be employed in symmetric RFBS (SRFBS). The main advantage of this concept, as described in details by Potash et al. ${ }^{18}$, is that the same species is dissolved in both tanks thereby minimizing the detrimental effects of membrane crossover. Moreover, in the discharged state, the two tanks contain solutions with identical composition, resulting in the absence of any chemical and electrochemical potentials across the cell. ${ }^{18}$ A few candidates for aqueous ${ }^{19-24}$ and non-aqueous 18,25-31 symmetric RFB electrolytes have 
been proposed recently, but no systematic study of structureproperty relationships has been reported to date. The common feature of molecules with two redox processes is the presence of (at least) two redox units. If one defines an SRFB as a device with the same composition of the tanks in the discharged state, one could think of a design where two different types of electroactive molecules are dissolved in both tanks. Then, one molecule acts as a posolyte and the other as a negolyte, while half of the material remains inactive. It is not immediately clear whether combining multiple redox units in the same molecule has advantages over such a trivial SRFB. This would be the case if there was a synergy between the redox units either in terms of voltage or solubility. The latter has been explored in combi molecules, where distinct posolyte and anolyte molecules have been covalently connected through solubility-enhancing linkers.19,21,23 In this contribution, we aim to answer the question whether installing multiple redox moieties on a compact molecular core can lead to additional synergies compared to directly mixing two types of electrolytes or combining them into one molecule through a linker. This is achieved by performing a systematic computational investigation of a class of three-ring candidate molecules for aqueous SRFBS and comparing the results with a judiciously chosen reference system composed of two molecules with just one redox moiety each (vide infra and Chart s1 in the Supporting 
Information). This choice gives us enough flexibility for the exploration of different multi-redox chemistries, while keeping the size of the molecules practically small. The objective of this study is to elucidate new structure-property relationships for bipolar SRFB materials and guide the subsequent experimental molecular design rather than propose a specific new material. Although long-term chemical stability is one of the main challenges in the design of molecules for aqueous RFBs, here we restrict the discussion to electrochemical properties and solubility in water. Our central hypothesis is that the electronic interaction between redox units offers an extra degree of freedom that can be exploited to tune the cell voltage of an SRFB. We will assess the magnitude of this interaction by comparing the potentials of molecules with multiple redox units to those of analogous molecules with a single redox unit.

We build a set of molecules based on an exemplary anthracenelike backbone, a popular template in many state-of-the-art electrolytes.6,9,10,32,33 We consider a range of prototypical template redox units (1,2-quinone, 1,4-quinone, pyrazine and pyridazine) and build each molecule by introducing two redox units on two of the aromatic rings. Additionally, we consider substitution of two aromatic carbons in the ring without redox-active groups with the oxygen, nitrogen and sulfur heteroatoms. When the heteroatom is nitrogen, this ring becomes a pyrazine, so the molecule effectively 
has three redox unit. The molecules with three redox units will be discussed separately. The resulting structures and their indexes are listed in Chart 1 . On a selected subset of these molecules (see ensuing discussion), we take one step further by adding electron-donating and electron-withdrawing substituents and discuss the impact on redox potentials and solubility. 
Chart 1. Structures of the considered electrolytes in their fully oxidized forms.<smiles>O=c1ccc(=O)c2c(=O)c3ccccc3c(=O)c1=2</smiles>

1<smiles>O=C1C=CC(=O)c2cc3nccnc3cc21</smiles>

7<smiles>O=C1C=CC(=O)c2nc3ccccc3nc21</smiles>

13<smiles>O=C1c2ccccc2C(=O)c2cnncc21</smiles>

19<smiles>c1cnc2cc3nccnc3cc2n1</smiles>

25<smiles>O=C1C=CC(=O)c2nc3cnncc3nc21</smiles>

31<smiles>O=c1ccc(=O)c2c(=O)c3occoc3c(=O)c12</smiles><smiles>O=c1ccc(=O)c2c(=O)c3sccsc3c(=O)c12</smiles>

3<smiles>O=c1ccc2c(=O)c3ccccc3c(=O)c=2c1=O</smiles>

4<smiles>O=c1ccc2c(=O)c3occoc3c(=O)c2c1=O</smiles><smiles>O=c1ccc2c(=O)c3sccsc3c(=O)c2c1=O</smiles><smiles>O=c1ccc(=O)c2oc3nccnc3oc1=2</smiles>

8<smiles>O=c1ccc(=O)c2sc3nccnc3sc1=2</smiles>

9<smiles>O=C1C=CC(=O)c2cc3cnncc3cc21</smiles>

10<smiles>O=c1ccc(=O)c2oc3cnncc3oc1=2</smiles>

11<smiles></smiles>

12<smiles>O=c1ccc(=O)c2nc3occoc3nc12</smiles><smiles>O=c1ccc(=O)c2nc3sccsc3nc12</smiles>

15<smiles>O=C1c2ccccc2C(=O)c2nccnc21</smiles>

16<smiles></smiles>

17<smiles></smiles>

18<smiles>O=c1c2sccsc=2c(=O)c2cnncc12</smiles>

21<smiles>O=c1ccc(=O)c2cc3c(=O)ccc(=O)c3cc12</smiles>

22<smiles>O=c1ccc(=O)c2oc3c(=O)ccc(=O)c3oc12</smiles>

23<smiles>O=c1ccc(=O)c2c(=O)c3nccnc3c(=O)c1=2</smiles>

28<smiles>O=c1ccc(=O)c2nc3c(=O)ccc(=O)c3nc12</smiles>

34<smiles>O=c1ccc2c(=O)c3nccnc3c(=O)c=2c1=O</smiles>

29<smiles>c1cnc2nc3nccnc3nc2n1</smiles>

35

The molecules with two redox units (1-27) are named double redox (DR) and can exist in three forms: fully oxidized (A), partially reduced $\left(\mathrm{AH}_{2}\right)$ and fully reduced $\left(\mathrm{AH}_{4}\right)$. Those with three redox units (28-35) are named triple redox (TR) have one further stable state 
$\left(\mathrm{AH}_{6}\right)$. We assume that all redox processes are concerted twoelectron, two-proton reactions, as is the case for most quinonelike species. ${ }^{6}, 14,14,22$ We evaluate the potentials in water at $\mathrm{pH}=0$, i.e. we consider all species fully protonated to avoid the computation of anions with charge $-2,-4$ and -6 which can be unreliable with density functional theory (DFT) and implicit solvation models. The redox potentials for the processes $\mathrm{A}+2 \mathrm{H}^{+}+2 \mathrm{e}^{-} \rightarrow \mathrm{AH}_{2}, \mathrm{AH}_{2}+2 \mathrm{H}^{+}+2 \mathrm{e}^{-} \rightarrow \mathrm{AH}_{4}$ and $\mathrm{AH}_{4}+2 \mathrm{H}^{+}+2 \mathrm{e}^{-} \rightarrow \mathrm{AH}_{6}$ are named $U_{1}, U_{2}$ and $U_{3}$ respectively, and the difference $\Delta U=U_{1}-U_{2}$ $\left(\Delta U_{\max }=U_{1}-U_{3}\right.$ in $\mathrm{TR}$ molecules $)$ is the maximum theoretical voltage of the battery. When the positions of the redox units are not equivalent (molecules 1-21), two different isomers of $\mathrm{AH}_{2}$ are possible, depending on which redox unit is reduced first. The energy differences between the two isomers are in the range 0.08$2.30 \mathrm{eV}$ for molecules 1-21; when it is small, it should be expected that a mixture of the two isomers can be produced when discharging the battery. For simplicity, we report the potential values determined by the more stable isomer of $\mathrm{AH}_{2}$, corresponding to the largest possible $\Delta U$. We follow the same approach for the TR molecules (28-35) and choose the most stable of the three isomers of the species $\mathrm{AH}_{2}$ and $\mathrm{AH}_{4}$.

For each molecule shown in chart 1 , the values of $U_{1}, U_{2}$ and $\Delta U$ are reported in Figure 1 .

ACS Paragon Plus Environment 


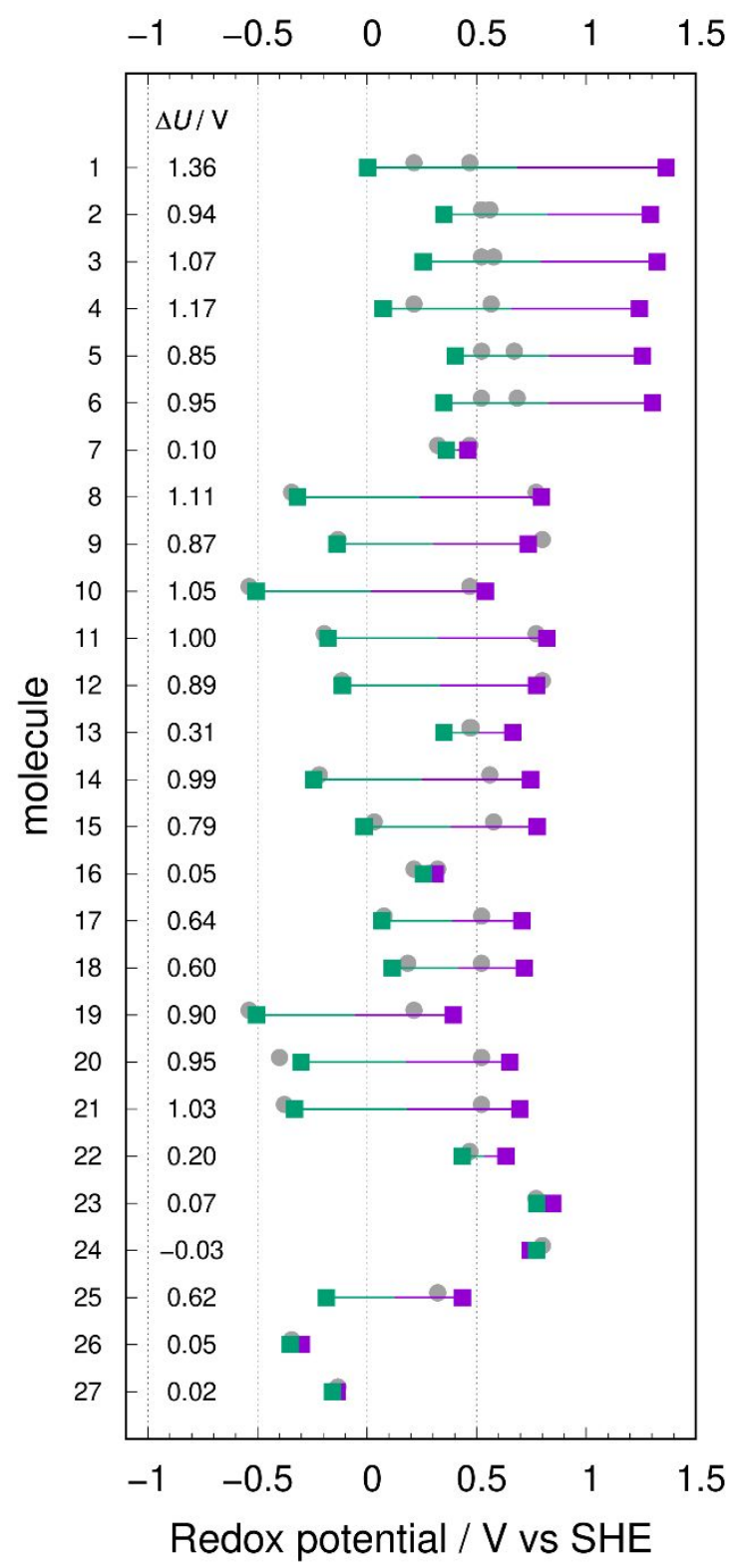

Figure 1. Redox potentials $U_{1}$ (purple) and $U_{2}$ (green) of molecules 1-27. $\Delta U=U_{1}-U_{2}$ values are listed on the left. The potentials of the single redox (SR) references of each molecule are represented by grey dots .

Some of the considered structures have been already proposed as RFB electrolytes. Derivatives of alizarin and quinizarin 
(molecules 1 and 4) have been recently reported to be good candidates for symmetric aqueous batteries; ${ }^{20,22}$ the calculated potentials and $\Delta U$ of 1 and 4 are consistent with the reported experimental values of alizarin and quinizarin derivatives. ${ }^{20,22}$ To understand how $\Delta U$ depends on the interaction between the two redox units on a small molecule, we computed for each molecule the redox potentials of two single redox (SR) reference molecules, which have only one of the redox units, while the other redox-active ring is just benzenic. For example, the SR references of molecule 8 are shown in Chart $\mathbf{s 1}$ (Supporting Information) and the difference between their redox potentials is $\Delta U_{S R}$. This choice of the reference structures is to a large extent arbitrary as stripping the quinone groups or replacing heteroatoms with carbons not only switches off the redox functionality but also induces global changes in the electronic structure of conjugated rings. Nevertheless, it is the conceptualy simplest way to gauge the interactions between multiple redox units on the same molecule. Because the objective of this work is to understand the advantages of merging multiple redox moieties in a single compact molecular core, the choice of reference molecules with the same size of the core is the most natural for such comparisons.

In molecules 1-8, where the redox units are both quinones, $\Delta U$ is considerably larger than $\Delta U_{S R}$. This can be interpreted as being due to the electronic interaction between the two non-equivalent 
quinone redox units when they are located on the same molecule. In molecule 1, for example, $\Delta U_{\mathrm{SR}}=0.25 \mathrm{~V}$ and $\Delta U=1.36 \mathrm{~V}$. However, we note that in molecules $1-8$, the increase of $\Delta U$ with respect to $\Delta U_{\mathrm{SR}}$ is predominantly due to $U_{1}$ shifting to higher potential rather than $U_{2}$ shifting to lower potential. In other words, the reduced species $\mathrm{AH}_{2}$ and $\mathrm{AH}_{4}$ are stabilized more than the oxidized species A with respect to the SR references. One reason for this stabilization is the electronic interaction between the (hydro) quinone units, which may be stronger in the more aromatic $\mathrm{AH}_{2}$ and $\mathrm{AH}_{4}$ than in the 'quinonic' $\mathrm{A}$. Additionally, we find that a significant component of the stabilization of the reduced species is the intramolecular $\mathrm{O}-\mathrm{H}---\mathrm{O}$ hydrogen bonding; an effect previously reported in literature. ${ }^{34}$ To estimate how much of the stabilization is due to hydrogen bonding, we compute for molecule 1 the energies of the conformers of $\mathrm{AH}_{2}$ and $\mathrm{AH}_{4}$ with the hydroxyl hydrogens pointing away from the oxygens, i.e. the less stable conformers without hydrogen bonding. As shown in the top panel of Figure 2, the stabilization of $\mathrm{AH}_{2}$ and $\mathrm{AH}_{4}$ with respect to their less stable conformers is indeed rather large, which results in a $+0.3 \mathrm{~V}$ shift of $U_{1}$ and a $+0.4 \mathrm{~V}$ increase of $\Delta U$ with respect to its conformer without hydrogen bonding (see bottom panel of Figure 2). Stabilization of the conformers is likely to be due to a combination of hydrogen bonding and reduced steric repulsion with neighboring hydrogens. A non-negligible conformer stabilization 
effect was found to be relevant in a few other molecules, for which comparisons analogous to Figure $\mathbf{2}$ are reported in Figure $\mathbf{s} 4$ (Supporting Information).
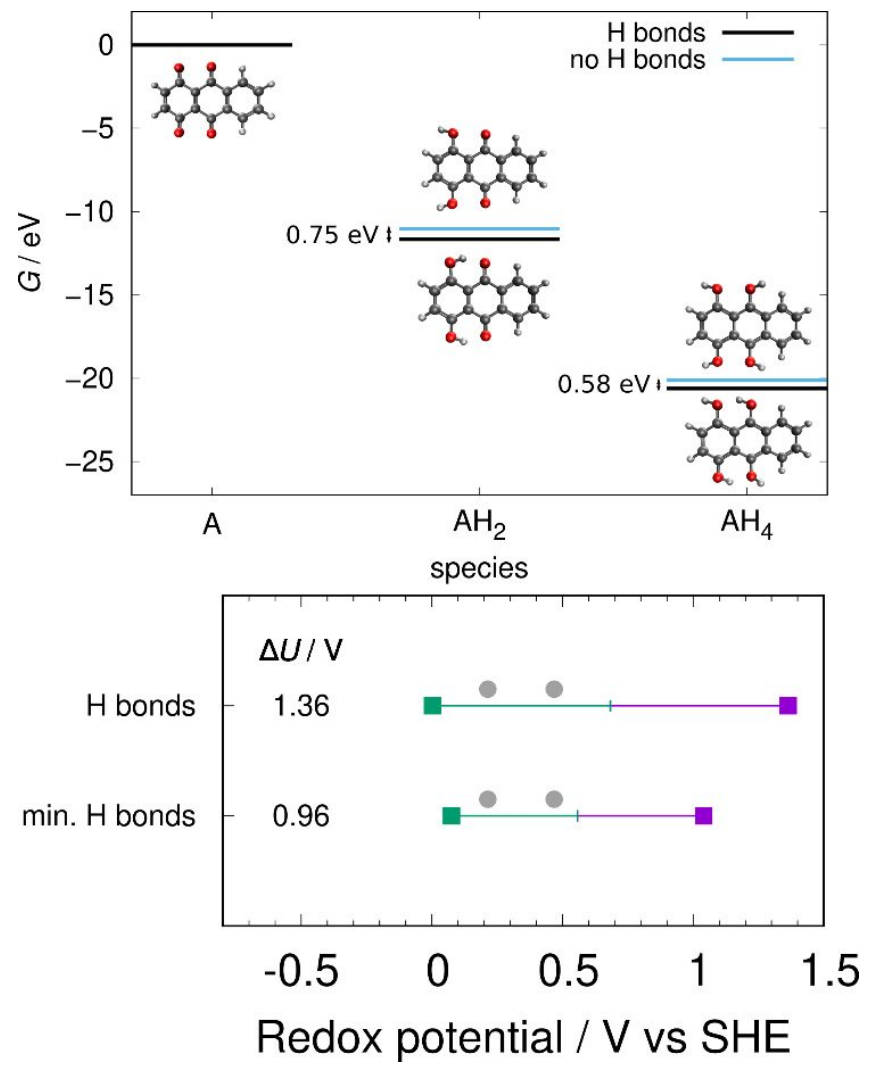

Figure 2. Top: Free energies (relative to the species A) and structures of the solvated reduced forms of molecule 1 . Free energies include the thermal correction $G_{\text {gas }}^{\text {corr }}$ and the solvation energy of the protons $n \Delta G_{\text {sol }}\left(H^{+}\right)$where $n=4,2,0$ for $\left(A, A_{2}\right.$, $\mathrm{AH}_{4}$ ). For the reduced species $\mathrm{AH}_{2}$ and $\mathrm{AH}_{4}$, the most stable conformer is in black and the conformer with the minimum number of intramolecular hydrogen bonds is in light blue. Bottom: Redox potentials of the conformers shown in the top panel (SR references in gray). 
The remaining difference between $\Delta U_{\mathrm{SR}}$ (gray) and $\Delta U$, without the effect of hydrogen bonds, can be attributed to the electronic interaction between quinones. This effect is observed mainly in molecules where two quinone units are on adjacent rings, where the electronic interaction is stronger and hydrogen bonding between quinone units is possible.

When the two redox units are different (molecules 7-21), the interactions between them appear in general to be weaker. In molecules 7-12, where the redox units are not on adjacent rings, the values of $U_{1}, U_{2}$ and $\Delta U$ are very similar to those of their SR references, which in 8-12 already have large $\Delta U_{\mathrm{SR}}$ values. In molecules 13-15 and 17-21, the significant $0.2 \mathrm{~V}$ positive shift of $U_{1}$ with respect to the $S R$ references is due to the electronic interaction between adjacent redox units; additionally, a weak $\mathrm{O}-\mathrm{H}---\mathrm{N}$ hydrogen bond may contribute to the stabilization of $\mathrm{AH}_{2}$ in molecule 18 (see Figure s4, Supporting Information). It is interesting to compare molecules 13 and 16 which are isomers and differ only by the location of the benzene ring: in molecule 16 , $\Delta U=0.05 \mathrm{~V}$ is smaller than $\Delta U_{\mathrm{SR}}=0.11 \mathrm{~V}$; in contrast, there is a large relative gain in $\Delta U$ for molecule 13 (from $0.01 \mathrm{~V}$ to $0.31 \mathrm{~V}$ ). This observation should serve as a warning that the interaction between redox units depends strongly on the electronic structure of the whole molecule and cannot always be guessed from the outset. In general, in the case of multiple redox moieties, the 
substituents can strongly interact with all of them, making building intuition harder. Therefore, in such cases accurate calculations of redox potentials should be included in molecular design workflows.

The changes in charge distribution and aromaticity in different redox states for a representative subset of molecules and their associated SR reference structures are shown in Figure s5 (Supporting Information) in the form of electrostatic potential (ESP) maps and nucleus-independent chemical shifts (NICS) which is a widely accepted measure of aromaticity. ${ }^{35}$ since aromaticity is only one of the components of electronic stabilization energy (which in turn determines the redox potentials), we limit this analysis to qualitative considerations following a recent example.24 In general, quinone units are non-aromatic and become aromatic when reduced, while pyrazine units are aromatic and become slightly anti-aromatic upon reduction. In molecule 1 the strong interaction between the quinone units is evidenced by the smaller change in aromaticity of the outer redox unit compared to its reference $\mathrm{SR}_{2}$ : when going from $\mathrm{A}$ to $\mathrm{AH}_{2}$, instead of becoming fully aromatic as in $\mathrm{SR}_{2}$, this hydroquinone shares some electronic density and quinone character with the middle quinone unit. Only when the latter is also reduced to $\mathrm{AH}_{4}$, the NICS values become more similar to those of the reduced SR references. In molecules 13 and 17 the interaction between the quinone and pyrazine redox units is 
evidenced by weaker aromatic and anti-aromatic character in the $\mathrm{AH}_{4}$ form compared to the SR references. In molecule 8, instead, the oxygen atoms make the middle ring slightly antiaromatic and there is no interaction between the redox units: here the ESP maps and NICS values are very similar to those of the SR reference structures.

In molecules 22-24, the quinone units are not on adjacent units, thereby weakening the interaction and preventing intramolecular hydrogen bonding. The $\Delta U$ values are around $0.2 \mathrm{~V}$ for the fully aromatic 22 (due to purely electronic interaction) and closer to $0 \mathrm{~V}$ for 23 and 24 where the aromaticity is interrupted by the heteroatoms, switching off also the electronic interaction between the redox units. The same pattern is observed in the group 25-27, where the aromatic 25 has large $\Delta U$ while in 26 and $27 \Delta U \sim 0 \mathrm{~V}$. We discuss next the redox potentials of molecules 28-35 which have three redox units. The results, shown in Figure 3, are consistent with the observations made so far: multiple redox units which are part of the same aromatic system can interact strongly and increase the maximum $\Delta U$. All molecules present a large positive shift of $U_{1}$ with respect to the SR reference, which indicates stabilization of the species $\mathrm{AH}_{2}$ with one of the quinone unit reduced as discussed before. $U_{3}$, which is due to the reduction of the pyrazine unit, is always shifted to lower potentials, with the only exceptions being molecules 31 and 33, where it is due to the 
pyridazine unit. Overall, the triple redox (TR) design strategy seems another promising way of tweaking the potentials and increasing the theoretical voltage of symmetric RFBs. It should be noted, however, that such a four-state battery, operating between potentials $U_{1}$ and $U_{3}$, would not be truly symmetric as the tanks would contain different species in the discharged state $\left(\mathrm{AH}_{2}\right.$ and $\left.\mathrm{AH}_{4}\right)$. Such even-state electrolytes may have certain disadvantages for SRFBs as noted by Potash et al. ${ }^{18}$ Nevertheless, it has to be noted that this situation is completely analogous to the Vanadium RFB, in which the vanadium ions are oxidized/reduced between the $\mathrm{V}^{2+} / \mathrm{V}^{3+}$ and $\mathrm{VO}^{2+} / \mathrm{VO}_{2}{ }^{+}$redox pairs. Despite not being completely symmetric, VRFB enables electrolyte rebalancing strategies that can be used to mitigate the membrane cross-over. 


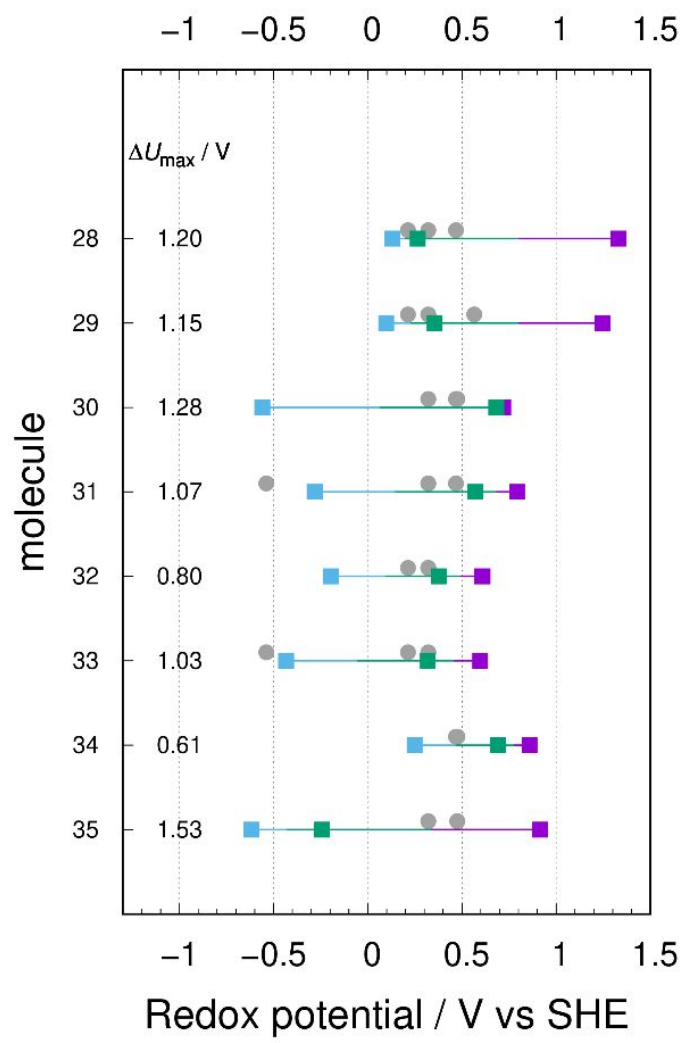

Figure 3. Redox potentials $U_{1}$ (purple), $U_{2}$ (green) and $U_{3}$ (blue) of molecules 28-35. $\Delta U_{\max }=U_{1}-U_{3}$ values are listed on the left. The potentials of the single redox (SR) references of each molecule are represented by grey dots.

In summary, we have identified two effects responsible for the increased theoretical voltage of a flow battery based on molecules with multiple redox units compared to the same units on separate molecules: i) electronic interaction between the redox units; ii) intramolecular hydrogen bonding between adjacent units. These effects are strongest in the double quinones 1-6 which can achieve $\Delta U$ in the range $0.85-1.36 \mathrm{~V}$ compared to $\Delta U_{S R}$ of $0.04-0.16 \mathrm{~V}$. When 
there are two different redox units, the gain with respect to the SR reference is smaller but can still be of significant magnitude. The interaction between three redox units can also yield significant gains in $\Delta U$.

Another crucial property for RFB electrolytes is the solubility. Although an accurate prediction of solubility is not in the scope of this letter, we are interested how it is affected by the presence of multiple redox units. We report in Figure 4 the solubilities (predicted with the ChemAxon Solubility Plugin ${ }^{36}$ ) of molecules $1-35$ and of their SR references in the solubilitylimiting redox form, which was chosen for each structure as the form with the lowest solubility.

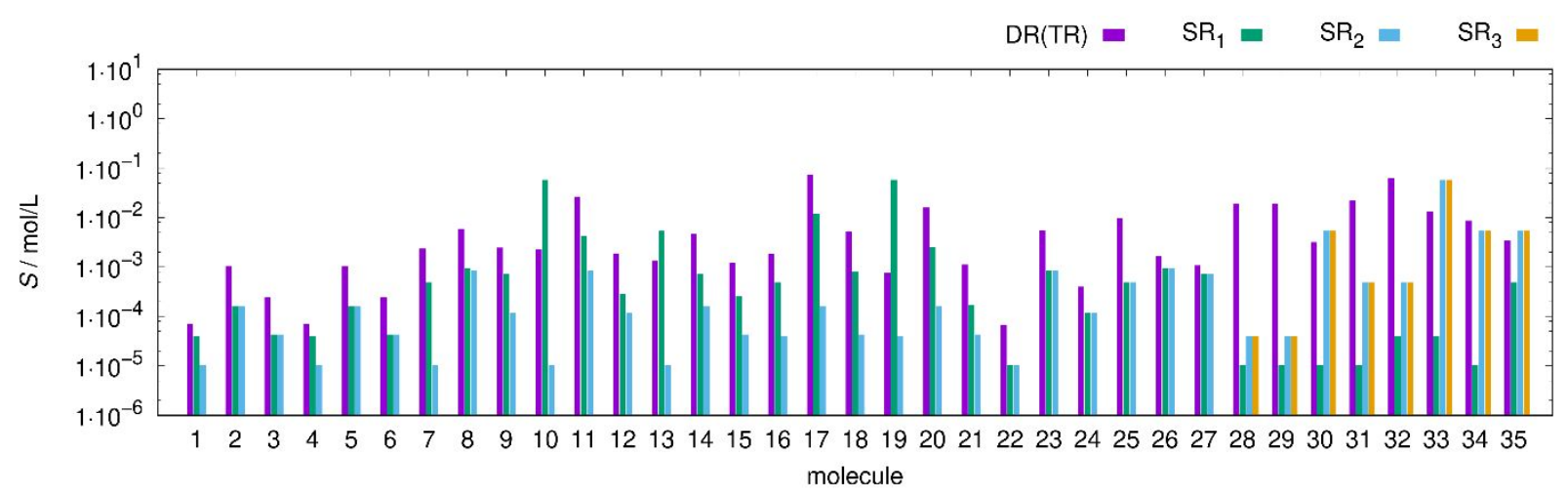

Figure 4. Solubility in water at $\mathrm{pH}=0$ computed with the ChemAxon Solubility Plugin ${ }^{36}$ of double and triple redox molecules (DR, TR) and of their single redox (SR) reference structures. Structures shown in Chart 1 .

The results show that multiple redox units often improve solubility with respect to molecules of the same size but with a 
single redox unit. This should be seen as a positive collateral effect stemming from the proposed design rule of multiple redox units on the same molecular core, whose primary goal is realizing symmetric electrolytes with high potential difference. Once a suitable compound has been found, various strategies can be employed to improve solubility: adding hydrophilic substituents, 4,10 decreasing the melting point by discouraging crystal packing ${ }^{37}$ and altering the composition of the electrolyte e.g. by adding chloride salts ${ }^{38}$ or exchanging sodium ions with larger hydrophilic organic cations. ${ }^{20}$

We investigate next the effects on the redox potentials of adding electron-donating and electron-withdrawing substituents to a subset of the structures in chart 1. We focus on molecules 1, 8 , 31 and 35 because they have large $\Delta U$ and are representative of the variety of structures considered. We choose as representative substituents the electron-donating methoxy group (OMe) and the electron-withdrawing sulfonic acid group $\left(\mathrm{SO}_{3} \mathrm{H}\right)$, whose effects on redox potentials of quinones are roughly the same but with opposite signs. ${ }^{10}$ To assess the substituent effect, we consider first single substitution at all available aromatic carbons, then double substitutions at selected positions (see subsequent discussion). The resulting structures are shown in Chart s2 (Supporting Information). The redox potentials and $\Delta U$ of the singly substituted molecules are shown in Figure s1 (Supporting Information). In 
general, OMe tends to shift potentials down and $\mathrm{SO}_{3} \mathrm{H}$ tends to shift the potentials up with respect to the unsubstituted molecule, in accordance with previous computational studies on quinones. ${ }^{10}$ In particular, we observe that in molecule 8 , where the redox units are different and are electronically isolated by the oxygen heteroatoms, the substituent effect is easier to rationalize. OMe has a very small effect when attached to the quinone unit (8a) but shifts $U_{2}$ down when attached to the pyrazine unit (8b). $\mathrm{SO}_{3} \mathrm{H}$ instead has a greater effect and shifts $U_{1}$ up when attached to the quinone unit (8c) and $U_{2}$ up when attached to the pyridazine unit (8d). Molecule 1 , however, is an exception to this tendency as $\Delta U$ becomes smaller with OMe in position 5 and with $\mathrm{SO}_{3} \mathrm{H}$ in any position. In the TR molecules (31 and 35), all potentials are in general shifted to lower values. The maximum $\Delta U$ is increased in some cases (8b, 8c, 31b, 31c, 35a). In summary, the effect of substituents on the redox potentials is easy to predict when the redox units do not interact strongly.

Since substituents are expected to affect the solubility, we report in Figure s3 (Supporting Information) the predicted solubilities of the substituted and unsubstituted compounds, each in the solubility-limiting redox form. While in most cases OMe substitution has little effect on solubility, $\mathrm{SO}_{3} \mathrm{H}$ mostly yields a significant increase of solubility which is not surprising since it is a hydrophilic group. 
With these considerations in mind, one can try to combine one electron-withdrawing and one electron-donating substituent (pushpull design strategy) on the same molecule with the goal of increasing $\Delta U$ (and therefore the theoretical voltage) while also improving solubility. To this end, we select molecules 8, 31 and 35. In molecules 8 and 31, we add $\mathrm{SO}_{3} \mathrm{H}$ to the quinone unit, which we expect to shift $U_{1}$ higher, and OMe to the other available redox unit, which should push $U_{2}$ lower, thereby obtaining an even larger $\Delta U$. In molecule 35, we adopt the same strategy. We consider both combinations of substitution positions and obtain the molecules $8 e, 8 f, 31 e, 31 f, 35 c$ and 35d, as shown in Chart s2 (Supporting Information). The redox potentials and $\Delta U$ of these push-pull doubly substituted molecules are reported in Figure s2 (Supporting Information). The proposed substitution design strategy proved successful in increasing the $\Delta U$ of molecule 8 from $1.11 \mathrm{~V}$ (unsubstituted) to $1.23 \mathrm{~V}$ (singly substituted with either ome or $\mathrm{SO}_{3} \mathrm{H}, 8 \mathrm{~b}$ or $8 \mathrm{C}$ ) and $1.33 \mathrm{~V}$ (doubly substituted with $\mathrm{OMe}$ and $\mathrm{SO}_{3} \mathrm{H}$, $8 d$ and 8f). The predictability of this effect is due to the fact that the two redox units are connected by two oxygen atoms which interrupt the aromatic system and thereby prevent electronic interaction between the redox units. Therefore, the potentials $U_{1}$ and $U_{2}$ of molecule 8 are individually tunable. In molecules 31 and 35, where the backbone is fully aromatic, the push-pull substitutions did not increase $\Delta U$ with respect to single 
substitutions. Finally, the double substitution did not significantly affect the solubility compared to single $\mathrm{SO}_{3} \mathrm{H}$ substitution (see Figure s3, Supporting Information).

Although the goal of this paper is elucidating structure-property relationships and proposing design rules rather than viable candidates for SRFBs, we report in Tables $\mathbf{S 1}$ and $\mathbf{s} 2$ (Supporting Information) the synthetic accessibility (SA) score computed with the RDKit-based implementation ${ }^{39}$ of the method described in ref. ${ }^{40}$ for all structures considered in all redox forms. A general trend is that molecules with multiple redox units are expected to be more difficult to synthesize than their SR counterparts. Those with more varied heteroatoms are predicted to be less accessible. Among the molecules with $\Delta U>0.8 \mathrm{~V}$, those easier to synthetize (with SA score of at least one of the redox forms below 2.6) are $1,4,19,28,29,32,34$ and 1a-f, where molecules 1 and 4 have already been synthesized and characterized in an SRFB setup.20,22

By computing the redox potentials and solubilities of a representative set of molecules with two and three redox units, we have understood how the interactions between redox units on the same molecule affect the redox potentials and the difference between them. The electronic interaction plays the biggest role in increasing the difference between the redox potentials, and it can be switched off by interrupting the aromatic system between the redox units. Intramolecular hydrogen bonds between redox units on 
neighboring rings tend to push the more positive potential to even higher values. The solubility of molecules with multiple redox units is found to be better than their single redox counterparts. Finally, by adding substituents one can fine-tune one or both potentials when the redox units are electronically separated, but substitution effects can be more unpredictable when they are part of the same aromatic system. In this letter we have outlined some fundamental structure-property relationships which enable us to establish guidelines for the design of organic electrolytes for aqueous SRFBs. A complete set of design rules should incorporate tuning of reduction potential, solubility, synthetic accessibility and stability. In this work we primarily have addressed the first, and to some extent the second and third, of these properties. The target for the reduction potential is to achieve as high cell voltage as possible while observing stability limits of the molecule itself and of the aqueous medium in contact with the carbon electrodes and the active materials. In practice this likely limits the cell voltage to $<1.5 \mathrm{~V}$. A symmetric electrolyte with large $\Delta U$ and improved solubility can be built in two ways: i) incorporating two or more equivalent redox units on the same aromatic backbone; ii) assembling two or more different redox units which already have a given $\Delta U_{S R}$ when on separate molecules. In the latter case, the units can be electronically connected or isolated if the $\Delta U_{\mathrm{SR}}$ needs to be increased or preserved. The choice of redox 
units also determines the absolute positions of the potentials: for example, the double quinone motif is likely to push the more positive potential further up. The potentials may then be tuned further by substitution, keeping in mind the considerations outlined above. The set of design rules outlined here forms a solid basis for future investigations with the goal of finding ideal organic electrolytes for symmetric aqueous redox flow batteries. COMPUTATIONAL METHODS

All energies are computed at the B3LYP/6-311G(d,p) level of theory with the Q-Chem 5.0 software. ${ }^{41}$ The energies in solution are computed with the conductor-like polarizable continuum model (CPCM) ${ }^{42-44}$ using a dielectric constant of 78.39 (water). The reduction potential (in V) for the generic reaction $\mathrm{A}+2 \mathrm{H}^{+}+2 \mathrm{e}^{-} \rightarrow \mathrm{AH}_{2}$ is calculated with the direct approach: ${ }^{45}$

$$
U=-\frac{1}{n e}\left(\Delta E_{\mathrm{sol}}+\Delta G_{\mathrm{gas}}^{\mathrm{corr}}+n \Delta G_{\mathrm{SOI}}\left(\mathrm{H}^{+}\right)\right)-U_{\mathrm{SHE}}
$$

where $n=2$ is the number of electrons and protons transferred, $e$ is the elementary charge and the energy differences are expressed in eV. $\Delta E_{\text {sol }}=E_{\text {sol }}\left(\mathrm{AH}_{2}\right)-E_{\text {sol }}(\mathrm{A})$ is the reaction energy computed as the energy difference between the solvated species at the gas phase geometry. $\Delta G_{\text {gas }}^{\text {corr }}=\Delta H_{\text {gas }}-T \Delta S_{\text {gas }}$ is the thermal correction to the reaction free energy ( $\Delta H_{\text {gas }}$ includes zero-point energy and vibrational enthalpy and $-T \Delta S_{\text {gas }}$ is the entropy contribution) computed from vibrational frequency calculations in gas phase at 
$298 \mathrm{~K}$. The solvation free energy of the proton $\Delta G_{\mathrm{sol}}\left(\mathrm{H}^{+}\right)$and the standard hydrogen electrode potential $U_{\text {SHE }}$ are set to values consistent with the C-PCM solvation model $(-11.335 \mathrm{eV}$ and $4.47 \mathrm{~V}$ respectively). ${ }^{46}$ The solvation free energy is computed as $\Delta G_{\text {sol }}=E_{\text {sol }}$ $-E_{\text {gas }}$ at the gas phase geometry.

ASSOCIATED CONTENT

Supporting Information. Chart explaining the concept of single redox reference structures, structures of molecules with electron-donating and electron-withdrawing substituents, redox potentials and solvation free energies of substituted molecules.

AUTHOR INFORMATION

Corresponding Authors

* E-mail: rocforddtu.dk, pdes@dtu.dk

Notes

The authors declare no competing financial interest. ACKNOWLEDGMENTS

This work was financially supported through an investment by Innovation Fund Denmark via the Grand Solutions project "ORBATS" file nr. 7046-00018B.

REFERENCES 
(1) Winsberg, J.; Hagemann, T.; Janoschka, T.; Hager, M. D.; Schubert, U. S. Redox-Flow Batteries: From Metals to Organic Redox-Active Materials. Angew. Chem. Int. Ed. 2017, 56, 686711. https://doi.org/10.1002/anie.201604925.

(2) Ding, Y.; Zhang, C.; Zhang, L.; Zhou, Y.; Yu, G. Pathways to Widespread Applications: Development of Redox Flow Batteries Based on New Chemistries. Chem 2019, 5, 1964-1987. https://doi.org/10.1016/j.chempr.2019.05.010.

(3) Weng, G.-M.; Yang, B.; Liu, C.-Y.; Du, G.-Y.; Li, E. Y.; Lu, Y.-C. Asymmetric Allyl-Activation of Organosulfides for HighEnergy Reversible Redox Flow Batteries. Energy Environ. Sci. 2019, 12, 2244-2252. https://doi.org/10.1039/C9EE00336C.

(4) Leung, P.; Shah, A. A.; Sanz, L.; Flox, C.; Morante, J. R.; Xu, Q.; Mohamed, M. R.; Ponce de León, C.; Walsh, F. C. Recent Developments in Organic Redox Flow Batteries: A Critical Review. J. Power Sources 2017, 360, 243-283. https://doi.org/10.1016/j.jpowsour.2017.05.057.

(5) Ding, Y.; Zhang, C.; Zhang, L.; Zhou, Y.; Yu, G. Molecular Engineering of Organic Electroactive Materials for Redox Flow Batteries. Chem. Soc. Rev. 2018, 47, 69-103. https://doi.org/10.1039/C7CS00569E.

(6) Wedege, K.; Dražević, E.; Konya, D.; Bentien, A. Organic Redox Species in Aqueous Flow Batteries: Redox Potentials, Chemical Stability and Solubility. Sci. Rep. 2016, 6, 39101. https://doi.org/10.1038/srep39101.

(7) Namazian, M.; Coote, M. L. Accurate Calculation of Absolute One-Electron Redox Potentials of Some Para-Quinone Derivatives in Acetonitrile. J. Phys. Chem. A 2007, 111, 7227-7232. https://doi.org/10.1021/jp0725883.

(8) Zhu, X.-Q.; Wang, C.-H. Accurate Estimation of the OneElectron Reduction Potentials of Various Substituted Quinones in DMSO and CH3CN. J. Org. Chem. 2010, 75, 5037-5047. https://doi.org/10.1021/jo100735s.

(9) Bachman, J. E.; Curtiss, L. A.; Assary, R. S. Investigation of the Redox Chemistry of Anthraquinone Derivatives Using Density Functional Theory. J. Phys. Chem. A 2014, 118, 88528860. https://doi.org/10.1021/jp5060777.

(10) Er, S.; Suh, C.; Marshak, M. P.; Aspuru-Guzik, A. Computational Design of Molecules for an All-Quinone Redox Flow Battery. Chem. SCi. 2015, 6, 885-893. https://doi.org/10.1039/C4SC03030C.

(11) Pineda Flores, S. D.; Martin-Noble, G. C.; Phillips, R. L.; Schrier, J. Bio-Inspired Electroactive Organic Molecules for Aqueous Redox Flow Batteries. 1. Thiophenoquinones. J. Phys. Chem. C 2015, 119, 21800-21809. https://doi.org/10.1021/acs.jpcc.5b05346. 
(12) Ding, Y.; Li, Y.; Yu, G. Exploring Bio-Inspired QuinoneBased Organic Redox Flow Batteries: A Combined Experimental and Computational Study. Chem 2016, 1, 790-801. https://doi.org/10.1016/j.chempr.2016.09.004.

(13)

Lin, K.; Gómez-Bombarelli, R.; Beh, E. S.; Tong, L.; Chen, Q.; Valle, A.; Aspuru-Guzik, A.; Aziz, M. J.; Gordon, R. G. A Redox-Flow Battery with an Alloxazine-Based Organic Electrolyte. Nat. Energy 2016, 1, 1-8. https://doi.org/10.1038/nenergy.2016.102.

Kwabi, D. G.; Lin, K.; Ji, Y.; Kerr, E. F.; Goulet, M.A.; De Porcellinis, D.; Tabor, D. P.; Pollack, D. A.; AspuruGuzik, A.; Gordon, R. G.; et al. Alkaline Quinone Flow Battery with Long Lifetime at $\mathrm{PH}$ 12. Joule 2018, 2, 1894-1906. https://doi.org/10.1016/j.joule.2018.07.005.

(15) Yang, Z.; Tong, L.; Tabor, D. P.; Beh, E. S.; Goulet, M.-A.; De Porcellinis, D.; Aspuru-Guzik, A.; Gordon, R. G.; Aziz, M. J. Alkaline Benzoquinone Aqueous Flow Battery for Large-Scale Storage of Electrical Energy. Adv. Energy Mater. 2018, 8, 1702056. https://doi.org/10.1002/aenm.201702056.

(16) Tabor, D. P.; Gómez-Bombarelli, R.; Tong, L.; Gordon, R. G.; Aziz, M. J.; Aspuru-Guzik, A. Mapping the Frontiers of Quinone Stability in Aqueous Media: Implications for Organic Aqueous Redox Flow Batteries. J. Mater. Chem. A 2019, 7, 1283312841. https://doi.org/10.1039/C9TA03219C.

(17) Goulet, M.-A.; Tong, L.; Pollack, D. A.; Tabor, D. P.; Odom, S. A.; Aspuru-Guzik, A.; Kwan, E. E.; Gordon, R. G.; Aziz, M. J. Extending the Lifetime of Organic Flow Batteries via Redox State Management. J. Am. Chem. Soc. 2019, 141, 80148019. https://doi.org/10.1021/jacs.8b13295.

(18) Potash, R. A.; McKone, J. R.; Conte, S.; Abruña, H. D. On the Benefits of a Symmetric Redox Flow Battery. $J$. Electrochem. Soc. 2016, 163, A338-A344. https://doi.org/10.1149/2.0971602jes.

(19) Winsberg, J.; Stolze, C.; Muench, S.; Liedl, F.; Hager, M. D.; Schubert, U. S. TEMPO/Phenazine Combi-Molecule: A Redox-Active Material for Symmetric Aqueous Redox-Flow Batteries. ACS Energy Lett. 2016, 1, 976-980. https://doi.org/10.1021/acsenergylett.6b00413.

(20) Carretero-González, J.; Castillo-Martínez, E.; Armand, M. Highly Water-Soluble Three-Redox State Organic Dyes as Bifunctional Analytes. Energy Environ. Sci. 2016, 9, $3521-$ 3530. https://doi.org/10.1039/C6EE01883A.

(21) Janoschka, T.; Friebe, C.; Hager, M. D.; Martin, N.; Schubert, U. S. An Approach Toward Replacing Vanadium: A Single Organic Molecule for the Anode and Cathode of an Aqueous Redox-Flow Battery. Chemistryopen 2017, 6, 216-220. https://doi.org/10.1002/open.201600155. 
(22) Tong, L.; Jing, Y.; Gordon, R. G.; Aziz, M. J. Symmetric All-Quinone Aqueous Battery. ACS Appl. Energy Mater. 2019, 2, 4016-4021. https://doi.org/10.1021/acsaem.9b00691.

(23) Zhu, Y.; Yang, F.; Niu, Z.; Wu, H.; He, Y.; Zhu, H.; Ye, J.; Zhao, Y.; Zhang, X. Enhanced Cyclability of Organic Redox Flow Batteries Enabled by an Artificial Bipolar Molecule in Neutral Aqueous Electrolyte. J. Power Sources 2019, 417, 8389. https://doi.org/10.1016/j.jpowsour.2019.02.021.

(24) Zhang, C.; Niu, Z.; Peng, S.; Ding, Y.; Zhang, L.; Guo, X.; Zhao, Y.; Yu, G. Phenothiazine-Based Organic Catholyte for High-Capacity and Long-Life Aqueous Redox Flow Batteries. Adv. Mater. 2019, 31, https://doi.org/10.1002/adma.201901052.

(25) Rasmussen, P. G. Electrical Storage Device Utilizing Pyrazine-Based Cyanoazacarbons and Polymers Derived Therefrom. US8080327B1, December 20, 2011.

Oh, S. H.; Lee, C.-W.; Chun, D. H.; Jeon, J.-D.; Shim, J.; Shin, K. H.; Yang, J. H. A Metal-Free and All-Organic Redox Flow Battery with Polythiophene as the Electroactive Species. J. Mater. Chem. A 2014, 2, 19994-19998. https://doi.org/10.1039/C4TA04730C.

(27) Duan, W.; Vemuri, R. S.; Milshtein, J. D.; Laramie, S.; Dmello, R. D.; Huang, J.; Zhang, L.; Hu, D.; Vijayakumar, M. ; Wang, W.; et al. A Symmetric Organic-Based Nonaqueous Redox Flow Battery and Its state of Charge Diagnostics by FTIR. J. Mater. Chem. $A$ 2016, 4, 5448-5456. https://doi.org/10.1039/C6TA01177B.

(28) Hagemann, T.; Winsberg, J.; Häupler, B.; Janoschka, T.; Gruber, J. J.; Wild, A.; Schubert, U. S. A Bipolar Nitronyl Nitroxide Small Molecule for an All-Organic Symmetric RedoxFlow Battery. NPG Asia Mater. 2017, 9, e340-e340. https://doi.org/10.1038/am.2016.195.

(29) Ma, T.; Pan, Z.; Miao, L.; Chen, C.; Han, M.; Shang, Z.; Chen, J. Porphyrin-Based Symmetric Redox-Flow Batteries towards Cold-Climate Energy Storage. Angew. Chem. 2018, 130, 3212-3216. https://doi.org/10.1002/ange.201713423.

(30) Charlton, G. D.; Barbon, S. M.; Gilroy, J. B.; Dyker, C. A. A Bipolar Verdazyl Radical for a Symmetric All-organic Redox Flow-Type Battery. J. Energy Chem. 2019, 34, 52-56. https://doi.org/10.1016/j.jechem.2018.09.020.

(31) Hunt, C.; Mattejat, M.; Anderson, C.; Sepunaru, L.; Ménard, G. Symmetric Phthalocyanine Charge Carrier for Dual Redox Flow Battery/Capacitor Applications. ACS Appl. Energy Mater. 2019, 2, 5391-5396. https://doi.org/10.1021/acsaem.9b01317.

(32) Lin, K.; Chen, Q.; Gerhardt, M. R.; Tong, L.; Kim, S. B.; Eisenach, L.; Valle, A. W.; Hardee, D.; Gordon, R. G.; 
Aziz, M. J.; et al. Alkaline Quinone Flow Battery. Science 2015, 349, 1529-1532. https://doi.org/10.1126/science.aab3033.

Gerhardt, M. R.; Tong, L.; Gómez-Bombarelli, R.; Chen, Q.; Marshak, M. P.; Galvin, C. J.; Aspuru-Guzik, A.; Gordon, R. G.; Aziz, M. J. Anthraquinone Derivatives in Aqueous Flow Batteries. Adv. Energy Mater. 2017, 7, 1601488. https://doi.org/10.1002/aenm.201601488.

(34) Armendáriz-Vidales, G.; Martínez-González, E.; CuevasFernández, H. J.; Fernández-Campos, D. O.; Burgos-Castillo, R. C.; Frontana, C. The Stabilizing Role of Intramolecular Hydrogen Bonding in Disubstituted Hydroxy-Quinones. Electrochimica Acta 2013, 110, 628-633. https://doi.org/10.1016/j.electacta.2013.05.123.

(35) Chen, Z.; Wannere, C. S.; Corminboeuf, C.; Puchta, R.; Schleyer, P. von R. Nucleus-Independent Chemical Shifts (NICS) as an Aromaticity Criterion. Chem. Rev. 2005, 105, 3842-3888. https://doi.org/10.1021/cr030088+.

(36) Calculator (Version 19.26.0) Developed by ChemAxon, 2019, Https://Chemaxon. Com/Products/Calculators-andPredictors; 2019.

(37) Wei, X.; Pan, W.; Duan, W.; Hollas, A.; Yang, Z.; Li, B.; Nie, Z.; Liu, J.; Reed, D.; Wang, W.; et al. Materials and Systems for Organic Redox Flow Batteries: Status and Challenges. ACS Energy Lett. 2017, 2, 2187-2204. https://doi.org/10.1021/acsenergylett.7b00650.

(38) Milshtein, J. D.; Su, L.; Liou, C.; Badel, A. F.; Brushett, F. R. Voltammetry Study of Quinoxaline in Aqueous Electrolytes. Electrochimica Acta 2015, 180, 695-704. https://doi.org/10.1016/j.electacta.2015.07.063.

(39) Ertl, P.; Landrum, G. SAscorer, Https://Github.Com/Rdkit/Rdkit/Blob/Master/Contrib/SA_Score/ Sascorer.Py; 2013.

(40) Ertl, P.; Schuffenhauer, A. Estimation of Synthetic Accessibility Score of Drug-like Molecules Based on Molecular Complexity and Fragment Contributions. J. Cheminformatics 2009, 1, 8. https://doi.org/10.1186/1758-2946-1-8.

(41) Shao, Y.; Gan, Z.; Epifanovsky, E.; Gilbert, A. T. B.; Wormit, M.; Kussmann, J.; Lange, A. W.; Behn, A.; Deng, J.; Feng, X.; et al. Advances in Molecular Quantum Chemistry Contained in the Q-Chem 4 Program Package. Mol. Phys. 2015, 113, 184-215. https://doi.org/10.1080/00268976.2014.952696.

(42) Cossi, M.; Rega, N.; Scalmani, G.; Barone, V. Energies, Structures, and Electronic Properties of Molecules in Solution with the C-PCM Solvation Model. J. Comput. Chem. 2003, 24, 669-681. https://doi.org/10.1002/jcc.10189. 
(43)

Truong, T. N.; Stefanovich, E. V. A New Method for Incorporating Solvent Effect into the Classical, Ab Initio Molecular Orbital and Density Functional Theory Frameworks for Arbitrary Shape Cavity. Chem. Phys. Lett. 1995, 240, 253-260. https://doi.org/10.1016/0009-2614(95)00541-B.

(44) Barone, V.; Cossi, M. Quantum Calculation of Molecular Energies and Energy Gradients in Solution by a Conductor Solvent Model. J. Phys. Chem. A 1998, 102, 1995-2001. https://doi.org/10.1021/jp9716997.

(45) Ho, J. Are Thermodynamic Cycles Necessary for Continuum Solvent Calculation of PKas and Reduction Potentials? Phys. Chem. Chem. 2014, 17, 2859-2868. https://doi.org/10.1039/C4CP04538F.

(46) Organic Electrochemistry, Fifth edition revised and expanded.; Hammerich, O., Speiser, B., Eds.; CRC Press, Taylor \& Francis Group: Boca Raton, 2016. 